\title{
The Present-Day Crustal 3D Movement and Geodynamic Mechanisms in Hainan Island
}

\author{
Yaxuan Hu${ }^{1}$, Jiuchang $\mathrm{Hu}^{2}$, Bin $\mathrm{Zhao}^{3}$, Shanlan Qin ${ }^{1}$ \\ ${ }^{1}$ Second Crust Monitoring and Application Center, China Earthquake Administration, Xi'an, China \\ ${ }^{2}$ Earthquake Administration of Hainan Province, Haikou, China \\ ${ }^{3}$ Earthquake Administration of Hubei Province, Wuhan, China \\ Email: happy_hu6921@sina.com
}

How to cite this paper: $\mathrm{Hu}, \mathrm{Y}$. X., Hu, J. C., Zhao, B., \& Qin, S. L. (2020). The Present-Day Crustal 3D Movement and Geodynamic Mechanisms in Hainan Island. Journal of Geoscience and Environment Protection, 8, 231-243.

https://doi.org/10.4236/gep.2020.85015

Received: March 16, 2020

Accepted: May 24, 2020

Published: May 27, 2020

\begin{abstract}
The characteristics of the present-day crustal three dimensional (3D) movement with GNSS data during 1999-2018 and the precise leveling data during 1970s-2018 in Hainan Island and its adjacent area are analyzed. Based on the data and the horizontal movement field in the region of Southeast Asia, we discuss how the horizontal velocities in Hainan and the continental margin of the South China block (SCB) are affected by the Eurasian plate, the India-Australia plate and the Philippine Sea plate. The results show the movement of Hainan Island is the same as SCB. The horizontal velocities of the continental margin in South China are different in the east and the west along the boundary of the Northeastern Coast block and Yangtze Block. In Hainan Island, the 3D movement is different in two regions divided by Baisha fault. The movement of SCB is affected by Indo-European collision and extrusion. The movement of the continental margin is affected by both the Pacific Ocean plate, the Philippine Sea plate, the expansion of the South China Sea (SCS), the hot materials underplating and subsequent lithospheric extension. The effect on the regional movement by the Australia plate is smaller, but it can cause co-seismic step to SCB when there had a giant earthquake in Sumatra which is caused by the convergence of the Australia with the Sunda Plate in the NE direction.
\end{abstract}

\section{Keywords}

3D Movement, Geodynamic Mechanisms, India-Australia Plate, Philippine Sea Plate, Hainan Island

\section{Introduction}

Hainan Island is situated at a plate boundary region with the Eurasian plate, the 
India-Australian plate and the Philippine Sea plate converged. The evolutionary history of geological tectonics is complex. It is not only affected by the interaction of the plates, also by the multi-stage expansion of the sea basin in the South China. The uniquely tectonic structures make it become the key area to understand the continental accretion, continental margin evolution and the formation of SCS in the southeast Asia (Figure 1). The characteristics of the structures caused by the tectonic movements in each phases of the long geological history (Fu, et al., 2010). A lot of developed fractures makes the geological structure became complicated (Xu, et al., 2003). The activities of volcanoes and earthquakes were intense and frequent in the rift zone of the north island and Leizhou peninsula. The M7.5 earthquake in Qionghai happened in 1605 . There are vertically and horizontally neotectonic movements. They were intermittently and slowly rising (Zhang, et al., 1984). Base on the GNSS data since 1998, the horizontal movement of Hainan and SCB is SEE and the differences of the value of the velocities are small (Li, et al., 2010; Hu et al., 2014; Hu et al., 2016). Based on the precise leveling data during 1950s-1980s, the vertical movement in the north island reveals the different in the two sides of Haikou-TunChang. It was ascending in the east and descending in the west (Zhu, 1988). The vertical movement uplifted relative to the level basis point (Xiuying port). The crust in the southwest of the island uplifted faster than that in the northeast. The inherited movement reveals by the data during 1970s-1990s (Hu, et al., 2018). In order to recognize the 3D crustal movement further and the influences from the surrounding plates in Hainan and its vicinity, the main area in $105^{\circ} \mathrm{E}-125^{\circ} \mathrm{E}$ and $16.5^{\circ} \mathrm{N}-30^{\circ} \mathrm{N}$ will be studied. The horizontal deformation is analyzed based on the GNSS observation during 1999-2018 and the vertical deformation since 1970s. The geodynamic mechanism is analyzed with the data and some other GNSS results of the adjacent areas.

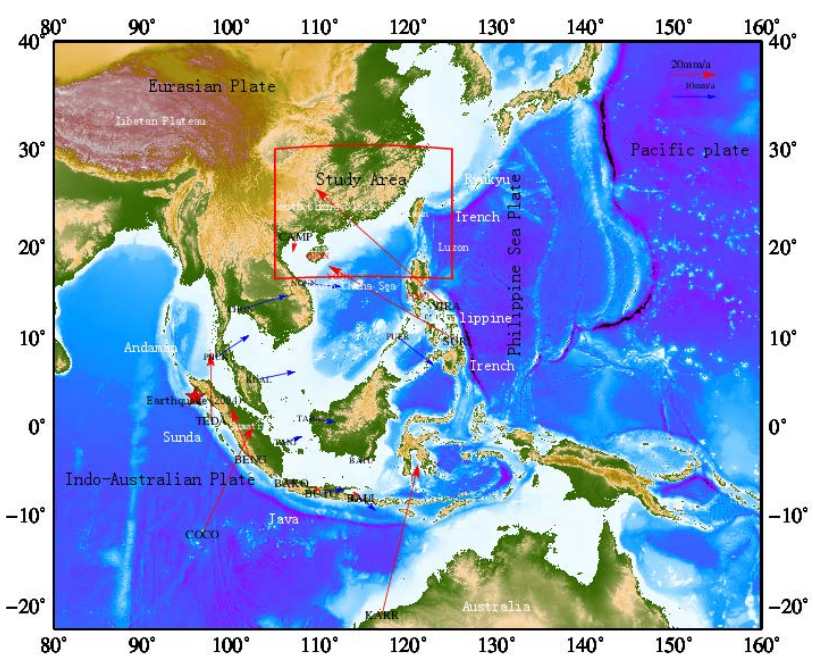

Figure 1. Studying area and Tectonic chart of the western Pacific margin(Red vectors in a frame of reference that minimizes the motion of ten sites situated on no-deformed Sundaland (Chamot-Rooke et al., 1999), Blue vectors with respect to BAKO in the ITRF97 reference frame (Becker et al., 2000). 


\section{3D Crust Movement in Hainan Island and SCB}

\subsection{Horizontal Movement}

\subsubsection{The Velocity Field of the Horizontal Movement}

Based on the continuous GNSS data since 1999 and the campaign data since 2009, the velocities of ITRF2014 are obtained by fitting (Table 1). The stations distribute at the margin of the island. The E-component of the velocities ranges from $29.12 \mathrm{~mm} / \mathrm{a}$ to $33.27 \mathrm{~mm} / \mathrm{a}$ and $\mathrm{N}$-component from $-8.71 \mathrm{~mm} / \mathrm{a}$ to -10.69 $\mathrm{mm} / \mathrm{a}$ (Figure 2). Divided by the Baisha fault, the E-component velocities of the stations in the west (more than $32.0 \mathrm{~mm} / \mathrm{a}$ ) are greater than that in the east(less than $32.0 \mathrm{~mm} / \mathrm{a})$.

The time series of the station coordinates show the changes in the periods and the influence of the strong earthquakes. The stations observed from 1999

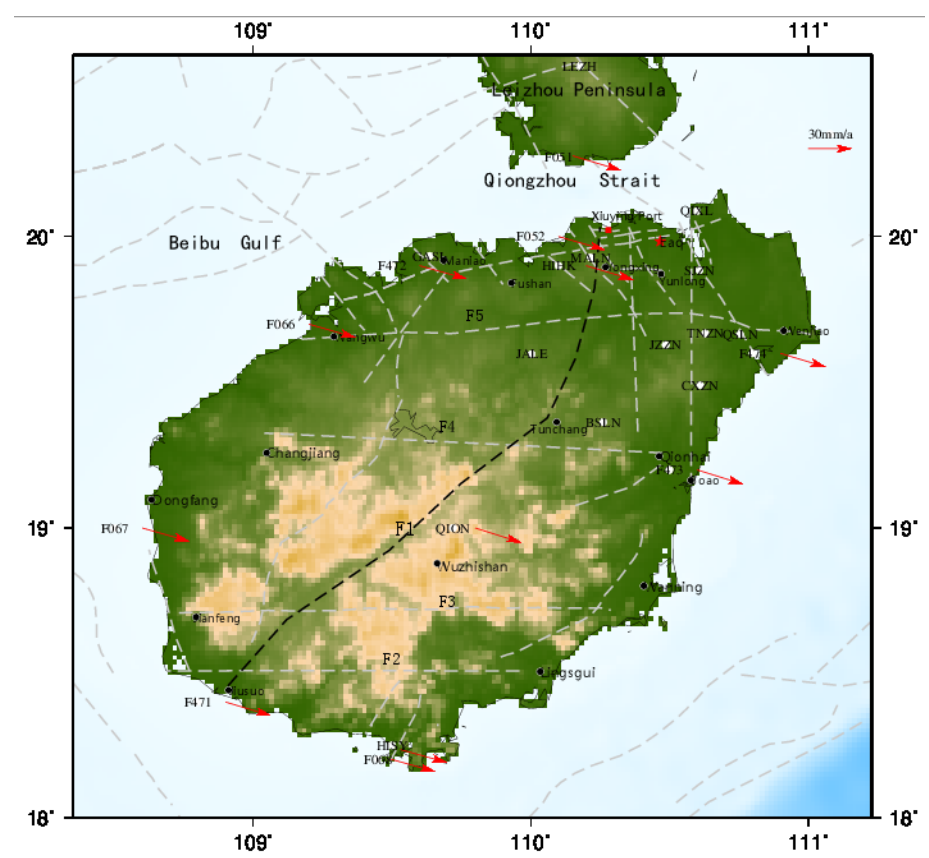

Figure 2. The velocites of the GNSS stations in Hainan Island (1999-2018) (ITRF2014). F1 Baisha Fault, F2 Jiusuo-Lingshui Fault, F3 Jianfeng-Wanning Fault, F4 Changjiang-Qionghai Fault, F5 Wangwu-Wenjiao Fault.

Table 1. The velocities of the GNSS stations in Hainan Island (1999-2018).

\begin{tabular}{ccccccccccccc}
\hline \multicolumn{4}{c}{ Stations in the West of Baisha Fault } & \multicolumn{4}{c}{ Stations in the East of Baisha Fault } \\
\hline Name & Lon. & Lat. & Ve & Vn & Time & Name & Lon. & Lat. & Ve & Vn & Time \\
\hline F066 & 109.2 & 19.7 & 32.2 & -9.25 & $1999.2-2017.6$ & F068 & 109.5 & 18.2 & 31.0 & -8.71 & $1999.2-2017.6$ \\
F067 & 108.6 & 19 & 32.3 & -9.19 & $1999.2-2017.6$ & HISY & 109.5 & 18.2 & 31.9 & -8.89 & $2010.7-2019.1$ \\
F472 & 109.6 & 19.9 & 32.5 & -9.18 & $2009.3-2017.6$ & F471 & 108.9 & 18.4 & 31.3 & -9.41 & $2009.4-2017.6$ \\
HIHK & 110.2 & 19.9 & 32.4 & -9.65 & $2010.6-2019.1$ & QION & 109.8 & 19.0 & 31.7 & -10.07 & $1999.2-2019.1$ \\
F052 & 110.1 & 20.0 & 32.0 & -9.32 & $1999.2-2017.5$ & F473 & 110.6 & 19.2 & 31.5 & -9.89 & $2009.4-2017.6$ \\
F051 & 110.1 & 20.2 & 33.3 & -10.12 & $1999.2-2017.5$ & F474 & 110.9 & 19.6 & 31.2 & -9.45 & $2009.4-2017.7$ \\
\hline
\end{tabular}


recorded the co-seismic changes caused by the Mw9.0 Earthquake happened on 2004/12/26 in Sumatra, Indonesia. After the earthquake the movement had been changing towards NW. Here, we take F052 and MALN (close to HIHK) as examples (Figure 3(a) and Figure 3(b)). It can be also seen that the trending horizontal direction is SE. The E-rates increases and it is about three times of the N-rates.

\subsubsection{Time Series of the Baseline Changes}

The station MALN is located in the center of the GNSS network in the northern island (Figure 3). The fifteen baselines relative to MALN are calculated respectively (Table 2). Most of the stations distribute in the east of MALN. The baselines are from $10.1 \mathrm{~km}$ to $87.4 \mathrm{~km}$. The nearest to MALN is the station F052 and the farthest is F474. The cumulative changes and average values of each baseline relative to the data in 2009 are calculated (Table 2). It shows that the baseline changes were fluctuating within $15 \mathrm{~mm}$ in general. The changes only in rarely years are the larger than $15 \mathrm{~mm}$. The E-component of the stations in Beibu Gulf and the north regions are larger than those in Hainan, but the difference is small.
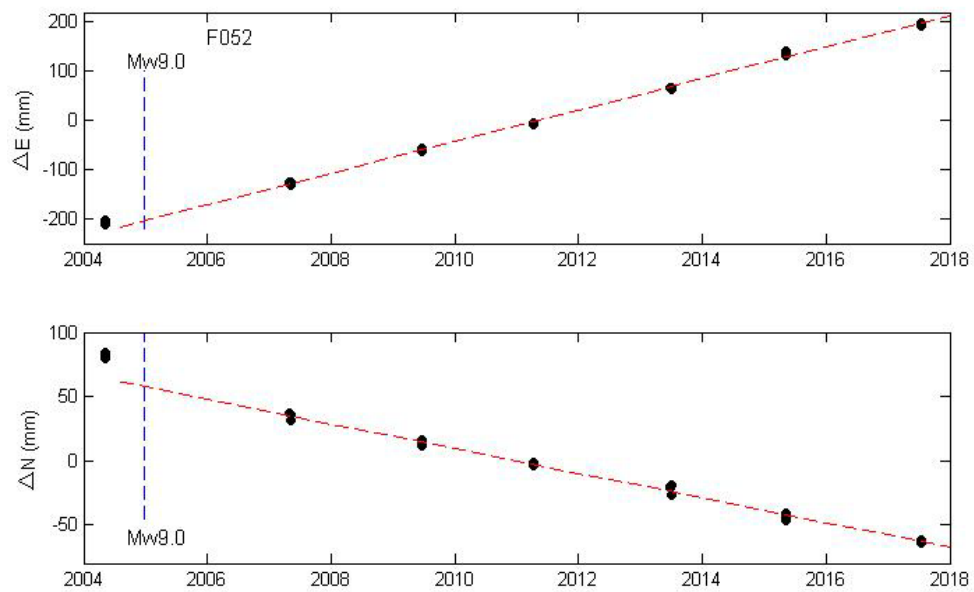

(a)
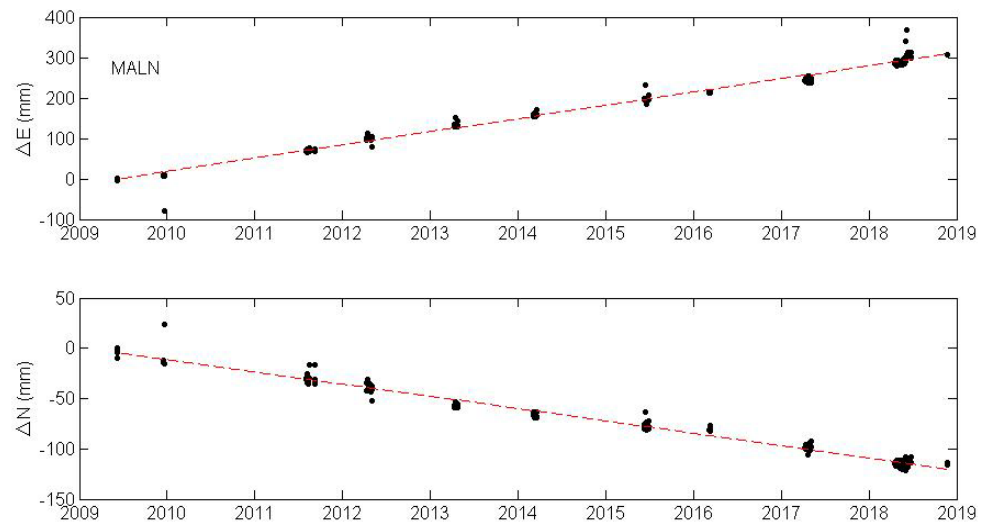

(b)

Figure 3. (a) Time series of the coordinates of F052; (b) Time series of the coordinates of MAIN. 
Table 2. Mean lengthes of the baselines (relative to MALN) and changes from 2009.

\begin{tabular}{|c|c|c|c|c|c|c|c|c|c|c|}
\hline \multirow{2}{*}{ BASELINE } & \multirow{2}{*}{$\begin{array}{l}\text { Length } \\
\text { (m) }\end{array}$} & \multicolumn{8}{|c|}{$\mathrm{dL}(\mathrm{mm})$} & \multirow{2}{*}{$\begin{array}{c}\text { MEAN } \\
(2018-2009) \\
\mathrm{mm} / \mathrm{a}\end{array}$} \\
\hline & & 2011-2009 & 2012-2009 & 2013-2009 & 2014-2009 & 2015-2009 & 2016-2009 & 2017-2009 & 2018-2009 & \\
\hline \multicolumn{11}{|c|}{ West in the MALN } \\
\hline MALN-JALE & $42,897.85$ & 10 & -1 & 7 & 2 & -1 & 6 & 2 & 12 & 1.33 \\
\hline MALN-GSLN & $60,615.56$ & 1 & 13 & - & 25 & -11 & -2 & 4 & -33 & -3.67 \\
\hline MALN-F472 & $54,529.17$ & - & - & - & 11 & - & 6 & - & - & - \\
\hline \multicolumn{11}{|c|}{ East in the MALN } \\
\hline MALN-F473 & $84,394.66$ & - & - & - & -17 & - & -12 & - & - & - \\
\hline MALN-F474 & $87,323.99$ & - & - & - & -12 & - & -9 & - & -17 & -1.89 \\
\hline MALN-BSLN & $62,728.84$ & 0 & 2 & -7 & -15 & -4 & -7 & -18 & -10 & -1.11 \\
\hline MALN-CXZN & $63,742.37$ & - & - & - & -15 & - & -11 & - & -18 & -2.00 \\
\hline MALN-JZZN & $43,733.16$ & - & - & - & -15 & - & -7 & - & -19 & -2.11 \\
\hline MALN-QIXL & $43,822.12$ & -8 & -11 & -13 & -3 & 0 & -3 & -1 & -7 & -0.78 \\
\hline MALN-QSLN & $63,512.27$ & - & -32 & -16 & - & 1 & -3 & -9 & -7 & -0.78 \\
\hline MALN-SJZN & $43,822.12$ & - & - & - & -11 & - & -7 & - & -32 & -3.56 \\
\hline MALN-TNZN & $41,419.8$ & - & - & - & -15 & - & -10 & - & -26 & -2.89 \\
\hline \multicolumn{11}{|c|}{ North in the MALN } \\
\hline MALN-LEZH & $72,361.47$ & 10 & 11 & 11 & 14 & 0 & 14 & 13 & 16 & 1.78 \\
\hline MALN-F051 & $38,969.75$ & - & - & - & - & - & - & - & $2^{*}$ & 1.00 \\
\hline MALN-F052 & $10,158.34$ & - & - & - & 13 & - & 13 & - & 15 & 1.67 \\
\hline
\end{tabular}

Note: ${ }^{*}$ the change of baseline are relative to that observed in 2016.

The results are the same as that by Wei et al. (2011). The changes are also confirmed the Ma'niao-Puqian fault with nearly EW direction is the seismogenic fault of the earthquake in 1605. It is tensional and normal fault and dextral strike-slip. Most of the baselines become shortened. The MALN-GSLN varies greatly. It may be related to the quality of the observed data. It needs further analysis. All the data show the baselines of the west stations to MALN tend to be elongated and stretched with the time gradually. The changes are relatively small. The baselines of the east stations to MALN are shortened by extrusion and the changes are greater with time. The baselines from MALN to F051, F052 and LEZH, which on the north region are less stretched.

\subsection{Vertical Movement}

The vertical deformation of the leveling route around the island observed in 1970s and 1990s showed the rising relative to the leveling site(Xiuying port)

(Figure 4). The velocities are calculated based on the linear-rate model (Hao, et al., 2014). A trending or an average movement over the decades is obtained. With Baisha fault as the boundary, the northwest of Jiusuo-Ma'niao rises about 


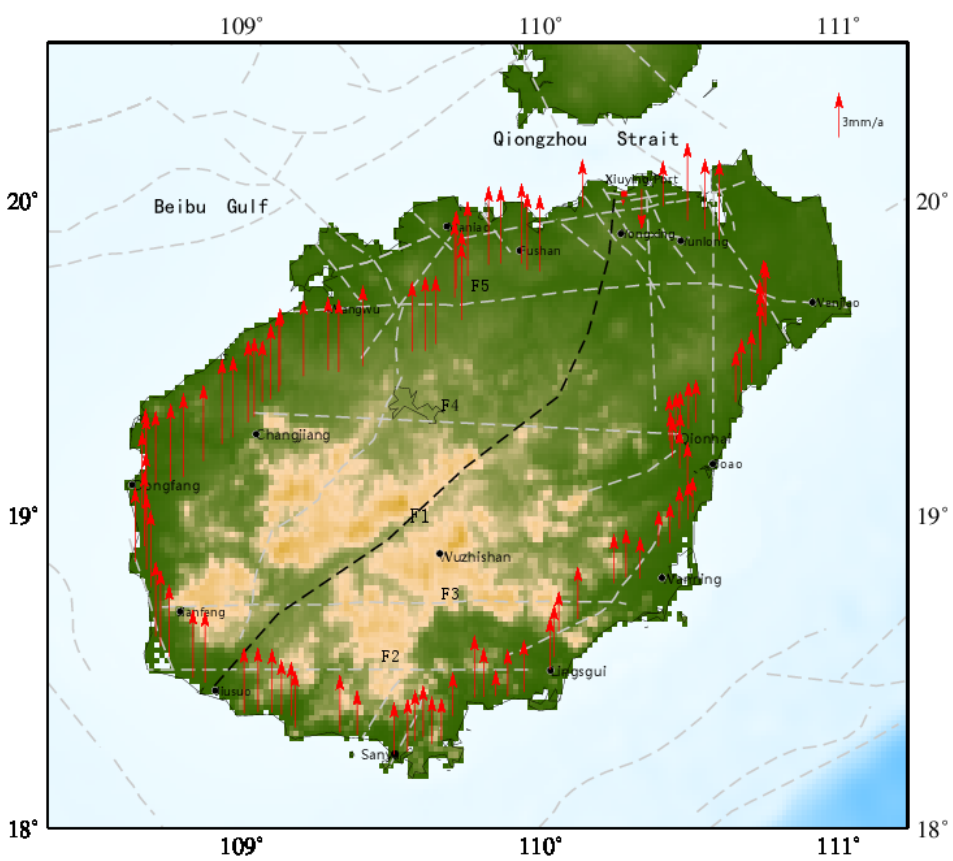

Figure 4. Vertical deformation rates during 1970s-1990s, Xiuying port was used as a reference point (the faults as Figure 2).

$1 \mathrm{~mm} / \mathrm{a}$ relative to the southeast of Bo'ao-Jiusuo. The overall movement is almostly consistent with the topography. Changjiang is the largest rising area. The north region of the Ma'niao-Puqian fault occurs decreasing. In addition, the vertical velocities by several other leveling routes in the northern Hainan Island observed in 1970s and 1990s showed that the trend is the east of Haikou-Tunchang uplift and subsidence in the west ( $\mathrm{Hu}$, et al., 2018). The movement is the same as that in 1957-1982 (Zhu, 1988). The boundary is just as the extension of Baisha fault.

\section{Geodynamic Mechanisms in the Area}

\subsection{Baisha Tectonic Belt}

Because of the unique geotectonic region, the island becomes important for studying on the formation and evolution of the land, the sea and the deep material movement. The Hainan block is adjacent to SCB, Indosinian block and SCS. The present block has been formed after multi-stage, multi-directional collision and consolidation, multi-stage deformation and metamorphism events (Xu, et al., 2003). There are different explanations about the tectonic framework and tectonic system, but most of them considered the framework was divided by Jiusuo-Lingshui fault and Changjiang-Qionghai fault (Zhang et al., 1997; Yang, et al., 1989; Li et al., 2000). Their results emphasized the E-W structural belt. In the central of the island, the Baisha fault locates in the southeastern margin of the Baisha Basin, which is another important tectonic belt for dividing the Hainan tectonic units. Metcalfe et al. (1993) thought the tectonic units were divided into the southeast block and the northwest block by the fault. After comparing 
the Cretaceous paleomagnetic data of Hainan and the southeastern margin of the South China plate, the results were attained that the difference of paleomagnetic data between the eastern and western sides of the Baisha fault in the Early Cretaceous, which indicates here exists a NE-trending strike-slip zone. It is believed that the structural belt along the coast of South China may be the southern extension of the Baisha fault. The belt may merge with the Changle-Nan'ao or Lishui-Haifeng fault zones along the southeastern coast, and formed an important and unified structural line in the eastern coastal areas. The difference of the present $3 \mathrm{D}$ crustal movement in the island is also characterized by the Baisha fault and the intra-island fault. The E-component of the velocities in the east of Baisha fault is smaller than that in the west. The vertical movement is consistent with the topography basically. The uplifting velocity is greater about $1 \mathrm{~mm} / \mathrm{a}$ in the northwest than that in the southeast. The horizontal velocities in the South China are also different in the sides with the boundary of the Cathaysian block, the Yangtze block and the Northeastern Coast block. It is nearly consistent with the boundary of the yellow line in Figure 5(a) and Figure 5(b). Especially in the continental margin of the Northeastern Coast block, the velocities and their difference become small. The E-component of the stations $(<33 \mathrm{~mm} / \mathrm{a})$ in the eastern continental margin is smaller than that in the western $(>33 \mathrm{~mm} / \mathrm{a})$. The S-component of the velocities $(<11 \mathrm{~mm} / \mathrm{a})$ on the west are smaller than that in the East $(>11 \mathrm{~mm} / \mathrm{a})$. The obvious boundaries are the longitudes $114^{\circ} \mathrm{E}$ and $118^{\circ} \mathrm{E}$ (Figure 5(c) and Figure 5(d)). The Changle-Nan'ao fault zone is considered the boundary between the normal continental crust of SCB and the thinning continental crust of the Taiwan Strait. The thickness of crust and lithosphere in coastal areas is significantly smaller than that in other areas. It is considered that the power from the subduction or the stretch-extension of the crust/mantle. The difference also can be found in the results by Wei et al., (2011). It may be a large intracontinental shear zone rather than a terrain suture zone (Wang et al., 2017). It also proves that the coastal fault zone is more like an early Cenozoic fault than a collision and junction zone between the northern margin of SCS and the South China plate (Wu, 1998).

\subsection{Influence of the Surrounding Plates}

What is the relationship between the movement of the studying area and that of the surrounding plates? The collision between the Indian plate and the Eurasian plate resulted in the uplift of the Qinghai-Tibet Plateau and the eastward and southeastward extrusion of material from the central part of the plateau. They push SCB to the eastward and southeastward. The crustal movement observed by GNSS has gradually changed from NE in western China to SEE in eastern China, and is roughly divided along the north-south Seismic Belt, where is a sudden change zone of the velocities. The spatial location is also consistent with the steep terrain in the eastern and western mainland (Ren et al., 2003). Affected by the collision of the peripheral plates, the Hainan block is supposed to experience a southward drift from Early Cretaceous to Pleistocene, a northward drift 


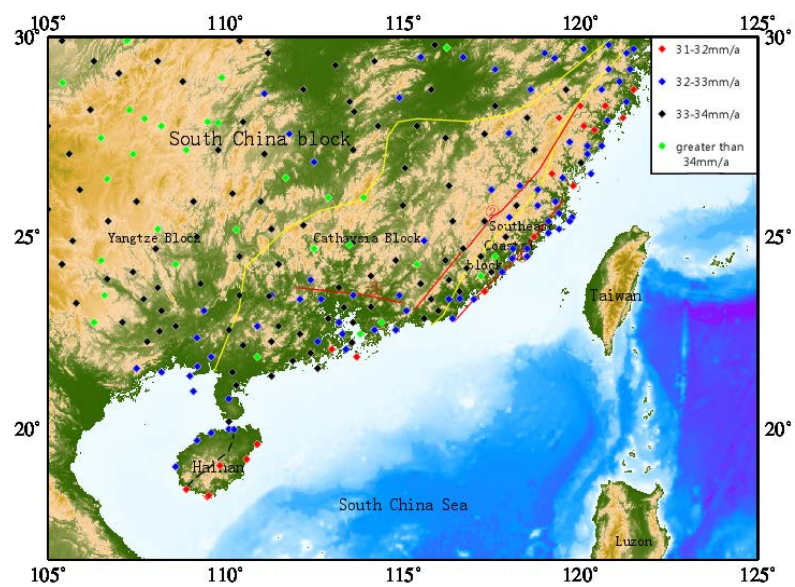

(a)

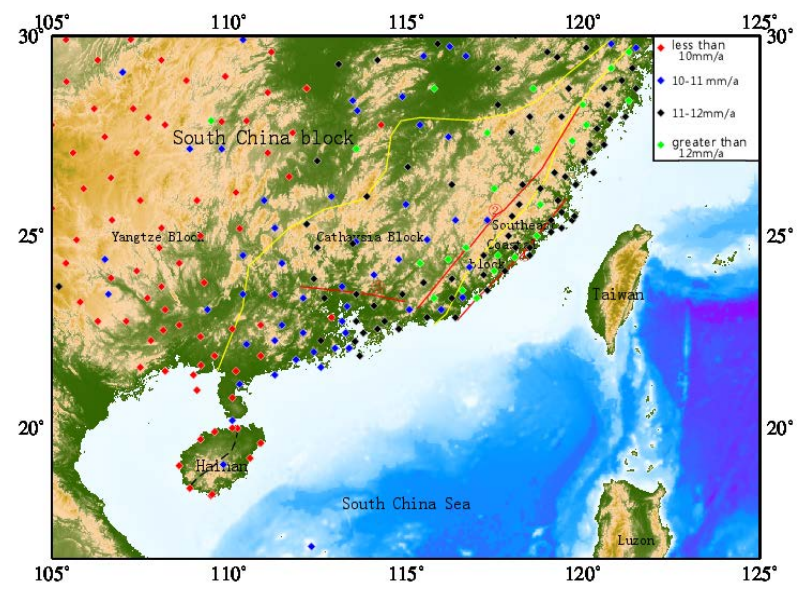

(b)

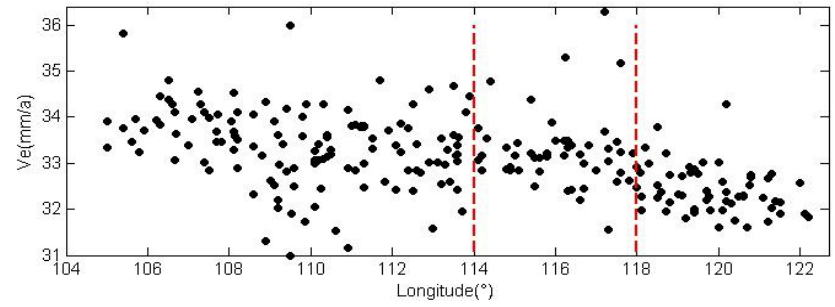

(c)

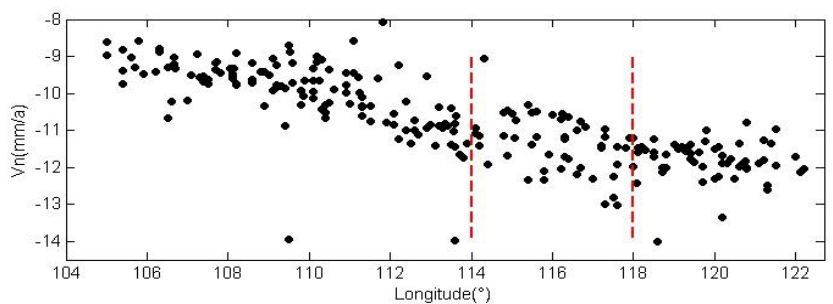

(d)

Figure 5. (a) Distributions of the E-velocities and the boundaries; (b) Distributions of the S-velocities and the boundaries. In (a) and (b), Yellow line, the boundary in the references (Zhang et al., 2002; Hong et al., 2002). Red line is the faults 1) Changle- Nan'ao fault, 2) Zhenghe-Dapu fault and 3) Gaoyao-Changning fault. (c) Distributions of E-velocities along the longitudes; (d) Distributions of N-velocities along the longitude. 
from Pleistocene to Holocene, and a clockwise rotation until now ( $\mathrm{Fu}$ et al., 2010). The southward drift of the island and the retreat of the subduction zone of the Pacific plate correspond to the development of large-scale NE-trending tensional faults and volcanic activity in the eastern of the Eurasian plate and the island. The present northward drift and rotation of the Hainan block may be influenced by the northwest subduction of the Philippine Sea plate to the Eurasian plate. The horizontal movement observed by GNSS reveals that the movement direction is basically the same from Indochina Peninsula to the continental shelf and then to the SCB, but the velocities increases gradually. The values and directions of the velocities in Hainan are similar to those of SCB (Hu et al., 2016). It is considered two blocks are moving as an integral one now. The pushing of the collision between Indo-European plates and the extrusion of the materials are influenced further by the NS and NW faults about $104^{\circ} \mathrm{E}$. It has less influence on Hainan Island from the Indosinian block. The present movement coincides with the result that the Hainan Block was basically connected with South China in the Late Paleozoic, and they move synchronously ( $\mathrm{Wu}, 1988)$. There is no obvious velocity gradient zone in SCB. The crust of South China, Taiwan and the East China is relatively integrated well. The crust of the island is one part of South China (Zhang et al., 1997).

The Australian plate moves NE to the Sunda Plate at the rate of $73 \mathrm{~mm} / \mathrm{a}$ in Sumatra island located in the southwestern of the Sumatra Fault (Wang, et al., 2011). The tectonic deformation is affected by the NE-trending subduction of the Australian plate obviously. When reaching the southwestern Sumatra, almost half of the deformation is consumed by the subduction and local compression. The rest is coordinated by the dextral strike-slip movement of the Sumatra fault, which limits the deformation within a narrow zone along the plate boundary. The crustal movement observed by GNSS on the northeastern side of the Sumatra fault is almost unaffected by the subduction (Cheng et al., 2001). The giant earthquakes in Sumatra caused by the NE movement of the Australian plate and the convergence of the plate and the Sunda plate, may produce co-seismic displacements in SCB. The Mw9.0 happened in 2004/12/26, the SSW/SW displacement to the epicenter was observed at the stations in SCB (Figure 6). Though the magnitude of the displacement is mostly $7-30 \mathrm{~mm} / \mathrm{a}$ (ITRF2014), the trend is small. The abnormal was observed before the earthquake by YONG and other continuous GNSS stations (Figure 1). Taking the E-component of QION as an example, the E-velocity accelerated beginning from 2004/12/13, and reversed to normal after the earthquake on 2004/12/26 (the co-seismic step was about $10.1 \mathrm{~mm}$ ) (Wang et al., 2011). The western Pacific marginal tectonic belt is different between the north and south bounded by Taiwan Island. Here, the Eurasian plate was torn up. In the south the southern Eurasian continental margin subducted beneath the Philippine island arc along the Manila Trench. In the north the Philippine ocean crust subducted beneath the Eurasian along the Ryukyu trench. This may be the reason for the east velocities in the eastern $115^{\circ} \mathrm{E}$ decrease (Figure 6). The Philippine island arc system is an 


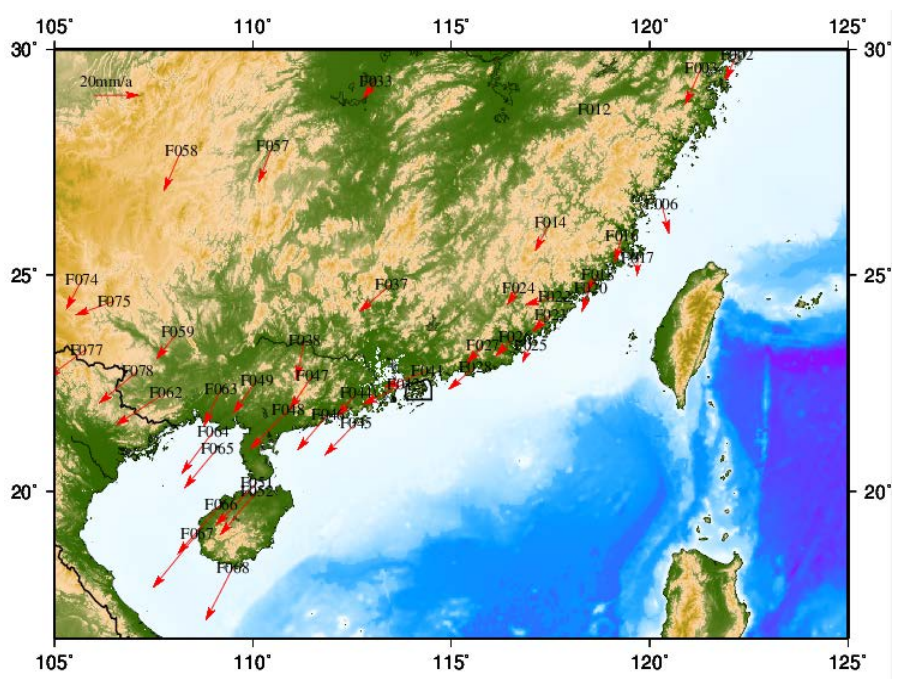

Figure 6. The co-seismic velocities of Mw9.0 in Sumatra on 2004/12/26.

active tectonic belt between the Philippine Sea plate and the Eurasian plate. It is composed of the complex island arcs, the continental blocks and two-way subduction zones. There include a large number of collision sutures and large strike-slip faults (Li et al., 2017). The subduction and collision of SCS basin from the Manila trench to Luzon Island resulted in the westward compression and strike-slip of the northeastern continental margin of SCS, and the movement of the southern Taiwan and the Philippines towards the mainland of China.

The expansion of SCS caused by the interaction among the Indian plate, the Pacific, the Philippine plate and the Eurasian plate, as well as the upwelling of mantle material in SCS did. The present horizontal movement shows that the velocities in the eastern of SCB are mainly influenced by the Philippine Sea plate, and the boundary of the force is mainly from the Luzon Island (Ren et al., 2003). The thrust of the NW direction from the Luzon Island towards to the central basin of SCS is greater than that of the Philippine Sea Plate towards to SCB. The baseline of YONG-PIMO shortened at a rate of $58.3 \mathrm{~mm} / \mathrm{a}(2009-2016)(\mathrm{Hu}$ et al., 2018). The central basin expands at a rate of $2.0-3.0 \mathrm{~mm} / \mathrm{a}$ with SN direction (Li et al., 2010). The QION-YONG baseline shortened at a rate of $4.1 \mathrm{~mm} / \mathrm{a}$ (2012-2015). The results indicated that the two islands compressed each other. It is inferred that the movement of the stations in the eastern Hainan is mainly influenced by the NW thrust when SCS basin subducts beneath Luzon Island and the expansion of SCS.

\section{Conclusion}

The above analysis reveals that the characteristics of 3D crustal movement in Hainan Island. The values and directions of the horizontal velocities of the Hainan block are consistent with that of SCB. Its movement is with SEE direction under ITRF framework. The movement of SCB is influenced by the Indo-European collision and extrusion, and the continental margin of the block influenced by the Pacific, Philippine and SCS plate movements. The Australian plate has little 
influence on the regional motion, while the Sumatra earthquake caused by the convergence of the NE and Sunda plates may cause the co-seismic jump to the stations in the island. The horizontal velocities in the continental margin of South China are different from that in the Yangtze block and in the Cathaysian block. The coastal margin has significantly smaller thickness of crust and lithosphere. In Hainan Island, the 3D crustal movement is mainly divided by the Baisha fault, the relative tension is at the western. The east and vertical movement is greater than that at the east, and the south movement is less than that at the east. The pushing from the collision of the Indo-European plate and the eastern flow of material are controlled by north-south faults located in $104^{\circ} \mathrm{E}$, the movement shifts to SE. The movements of the stations in the eastern of the Baisha fault are mainly influenced by the thrust of the Luzon Island with the NW direction and the expansion of the central basin. The velocities decrease. At the same time, the movement is also affected by the intra-island faults, resulting the tension and pressure in some area of the island. The western part is mainly influenced by the Eurasian plate. It is weakly influenced by the Indian-Australian plate in the south.

\section{Acknowledgements}

We are grateful to Professor Liu Mian, who gives us some good advice about the geodynamic research in the paper.

\section{Conflicts of Interest}

The authors declare no conflicts of interest regarding the publication of this paper.

\section{References}

Becker, M., Reinhart, E., Nordin, S. B., Angermann, D., Michel, G., \& Reigber, C. (2000). Improving the Velocity Field in South and South-East Asia: The Third Round of GEODYSSEA. Earth Planets Space, 52, 721-726. https://doi.org/10.1186/BF03352271

Chamot-Rooke, N., \& Le Pichon, X. (1999). GPS Determined Eastward Sundaland Motion with Respect to Eurasia Confirmed by Earthquakes Slip Vectors at Sunda and Philippine Trenches. Earth and Planetary Science Letters, 173, 439-455. https://doi.org/10.1016/S0012-821X(99)00239-3

Cheng, Z. Y., \& Zhu, W. Y. (2001). Crustal Deformation of Asia Pacific Area Determined by the GPS Data of APRGP97 - APRGP99. Acta Seismologica Sinica, 23, 268-279. https://doi.org/10.1007/s11589-001-0006-6

Fu, L. L., Shen, Z. Y., He, L., Dong, C. W., Cheng, X. M., Tang, L. M. et al. (2010). Cretaceous Paleomagnetic Results from Hainan Island and its Tectonic Implications. Acta Geologica Sinica, 84, 183-194.

Hao, M., Wang, Q. L., Shen, Z. K., Cui, D. X., Ji, L. Y., Li, Y. H. et al. (2014). Present Day Crustal Vertical Movement Inferred from Precise Leveling Data in Eastern Margin of Tibetan Plateau. Tectonophysics, 632, 281-292. https://doi.org/10.1016/j.tecto.2014.06.016

Hong, D. W., Xie, X. L., \& Zhang, J. S. (2002). Geological Significance of the Hangzhou- 
Zhugaungshan-Huashan High- $\varepsilon_{\text {Nd }}$ Ranite Belt. Geological Bulletion of China, 21, 348-354.

Hu, Y. X., Hu, J. C., \& Hao, M. (2014). Present Three-Dimensional Crustal Deformation in Hainan Island. Geodesy and Geodynamics, 5, 32-37. https://doi.org/10.3724/SP.J.1246.2014.02032

Hu, Y. X., Hao, M., Ji, L. Y., \& Song, S. W. (2016). Three-Dimensional Crustal Movement and the Activities of Earthquakes, Volcanoes and Faults in Hainan Island, China. Geodesy and Geodynamics, 7, 284-294. https://doi.org/10.1016/j.geog.2016.05.008

Hu, Y. X., Hao, M., Qin, S. L., Ji, L. Y., \& Song, S. W. (2018). Present-Day 3D Crustal Motion and Fault Activities in Hainan Island. Chinese Journal of Geophysics, 61, 2310-2321.

Li, X. H., Zhou, H. W., Ding, S. J., Lee, C. Y., Zhang, R. J., Zhang, Y. M. et al. (2000). Sm-Nd Isotopic Constraints on the Age of the Bangxi-Chenxing Ophiolite in Hainan Island: Implications for the Tectonic Evolution of Eastern Paleo-Tethys. Acta Petrologica Sinica, 16, 425-432.

Li, X. J., Wang, Z., Yao, Y. J., Gao, H. F., \& Li, B. (2017). The Tectonic Features and Evolution of the West Pacific Margin. Geology in China, 44, 1102-1114.

Li, Y. X., Zhang, J. H., Zhu, W., Luan, X. W., Hu, X. K., \& Zhang, Z. F. (2010). Current Tectonic Movement of South China Sea. Journal of Geodesy and Geodynamics, 30, $10-16$.

Metcalfe, I., Shergold, I. H., \& Li, Z. X. (1993). IGCP 321 Gondwana Dispersion and Asian Accretion: Fieldwork on Hainan Island. Episodes, 16, 443-447.

Ren, J. W., \& Ma, Z. J. (2003). Crustal Movement and Tectonic Deformation of Eastern Asia. Earth Science Frontiers, 10(Suppl.), 58-65.

Wang, M., Jiang, Z. S., Wu, Y. Q., \& Feng, Z. J. (2011). Far Field Horizontal Micro-Dynamic Crustal Deformations before and after Indonesia Mw9.0 Earthquake. Journal of Geodesy and Geodynamics, 31, 29-33.

Wang, S., Qiu, X. L., Zhao, M. H., Yan, P., Chen, X. Z., Li, P. C. et al. (2017). Imaging Crustal Structure Variation across the Changle-Nan'ao Fault Zone by the Joint Inversion of Seismic and Gravity Data. Chinese Journal of Geophysics, 60, 3853-3862.

Wei, Z. Q., Liu, G. M., \& Wu, F. M. (2011). China Geodetic Coordinate System 2000: Velocity Field in Mainland China. Acta Geodaetica et Cartographica Sinica, 40, 403-410.

Wu, J. M. (1998). Some Problems on the Geological Tectonic Evolution in South China Sea. Academic Proceedings of celebrating the 50th anniversary of the work of Academician Liu Guangding (pp. 61-73). Beijing: Science Press.

Xu, D. R., Chen, G. H., Xia, B., \& Chen, T. (2003). Comment on Several Important Basic Geological Problems in Hainan Island, China. Geological Science and Technology Information, 22, 37-44.

Yang, S. F., Yu, Z. Y., Guo, L. Z. et al. (1989). Block Division of Hainan Island, Paleomagnetic Study and its Significance in Plate Tectonics. Journal of Nanjing University (Earth Sciences), 1(1-2), 38-46.

Zhang, H. N., \& Zhao, X. T. (1984). Characteristics of the Neotectonic Movement in the Hainan Island and Leizhou Peninsula Area. Scientia Geologiga Sinica, (3), 276-287.

Zhang, J. S., \& Hong, D. W. (2002). The Division of South China Continent into Different Blocks Based on Geophysical Evidence and Comparison of Geochemical Features in Different Regions. Acta Geoscientia Sinica, 23, 147-152.

Zhang, Y. M., Zhang, R. J., Yao, H. Z., \& Ma, G. G. (1997). The Precambrian Crustal Tectonic Evolution in Hainan Island. Earth Science-Journal of China University of 
Geoscience, 22, 395-400.

Zhu, Y. H. (1988). The Crust Vertical Deformation Field in Northern Hainan (pp. 72-77). Beijing: The Earthquake Publishing House. 